\title{
Elastic Anisotropy and Its Temperature Dependence of the Single Crystals of Fe-19.43\% Cr Alloy*
}

\author{
By Hakaru Masumoto** and Michio Kikuchi**
}

\begin{abstract}
Rod-form single crystals of $\mathrm{Fe}-19.43 \% \mathrm{Cr}$ alloy of the $b c c$ type about $3 \mathrm{~mm}$ in diameter and $12 \mathrm{~cm}$ in length were prepared. The thermal expansion and Young's modulus in the temperature range $-150^{\circ}$ to $250^{\circ} \mathrm{C}$ and the rigidity modulus at $20^{\circ} \mathrm{C}$ of the alloy were measured by means of a dilatometer, a vibrator-controlled oscillator system and the torsion pendulum method, respectively. The results of calculations based on the measured values have shown that the Young's moduli of the single crystals at $20^{\circ} \mathrm{C}$ in the $\langle 100\rangle,\langle 110\rangle$ and $\langle 111\rangle$ directions are $14.22 \times 10^{5}, 22.23 \times 10^{5}$ and $27.37 \times 10^{5}$ $\mathrm{kg} / \mathrm{cm}^{2}$, and the rigidity moduli at $20^{\circ} \mathrm{C}$ are $11.36 \times 10^{5}, 7.21 \times 10^{5}$ and $6.43 \times 10^{5} \mathrm{~kg} / \mathrm{cm}^{2}$, respectively ; the elastic anisotropy is not very large in all cases. The Young's modulus in the $\langle 111\rangle$ shows a small minimum at $10^{\circ} \mathrm{C}$ and a small maximum at about $110^{\circ} \mathrm{C}$ with increasing temperature, while the Young's moduli in the $\langle 100\rangle$ and $\langle 110\rangle$ directions monotonously decrease. The mean temperature coefficients of Young's modulus at $10^{\circ} \sim 110^{\circ} \mathrm{C}$ are $-32.77 \times 10^{-5},-9.85$ $\times 10^{-5}$ and $+4.71 \times 10^{-5}$ in the $\langle 100\rangle,\langle 110\rangle$ and $\langle 111\rangle$ directions, respectively. The calculated value of Young's modulus for the polycrystal agrees fairly well with the measured value for the polycrystal specimen prepared by melting.
\end{abstract} (Received August 4, 1970)

\section{Introduction}

In a previous paper ${ }^{(1)}$ the present authors and Sawaya carried out measurements of the mean temperature coefficient of Young's modulus at $0^{\circ} \sim 40^{\circ} \mathrm{C}$ for $\mathrm{Fe}-\mathrm{Cr}$ polycrystal alloys containing $4.7 \sim 59.10 \% \mathrm{Cr}$. The result that the $\mathrm{Fe}-19.43 \% \mathrm{Cr}$ alloy showed the lowest negative value of $-6.81 \times 10^{-5}$. It was reported from this result that the Elinvar property was revealed in this system ${ }^{(2)}$. Therefore, it is a problem of great interest to investigate the variation in the temperature coefficient of elasticity with crystal direction in these $\mathrm{Fe}-\mathrm{Cr}$ alloys. The present study was carried out so as to examine the temperature dependence of elastic anisotropy in single crystals of the $\mathrm{Fe}-19.43 \% \mathrm{Cr}$ alloy with various directions.

\section{Experimental Procedure}

The alloying materials used were electrolytic iron and electrolytic chromium whose chemical compositions are tabulated in Table 1. For the preparation of specimens, a wire of $2 \mathrm{~mm}$ diameter with a composition of $80.57 \%$ $\mathrm{Fe}$ and $19.43 \% \mathrm{Cr}$ was at first prepared, from which single crystal specimens were produced by the TammannBridgman method ${ }^{(3)}$. The single crystals with rod axes near to the $\langle 110\rangle$ direction ${ }^{(4)}$ were most easily obtainable and the optimum descending rate of the crucible for their growth was $0.07 \mathrm{~mm} / \mathrm{min}$. However, since the single crystals of the $\langle 100\rangle$ and $\langle 111\rangle$ directions could hardly be obtained by the Tammann-Bridgman method alone, even though the descending rate of the crucible was changed, crystals of a desired directions were produced by adapting Fujiwara's method ${ }^{(5) \sim(8)}$. The optimum descending rate of the crucible for development of the two directions was $0.05 \mathrm{~mm} / \mathrm{min}$.

The single crystals of about $3 \mathrm{~mm}$ diameter thus were cut to the length of $12 \mathrm{~cm}$ and used as specimens for Young's modulus measurement. The orientation of the specimen was determined by the light-figure method ${ }^{(9)}$ after corroding in a $15^{\circ} \mathrm{C}$ mixture of $99 \mathrm{cc}$ of $\mathrm{Fe}_{3} \mathrm{Cl}$ and $1 \mathrm{cc}$ of $\mathrm{Br}$ for about $20 \mathrm{~min}$. For measurements of Young's modulus and the rigidity modulus, quasi-isotropic

Table 1 Chemical compositions of iron and chromium used

\begin{tabular}{c|c|c|c|c|c|c|c}
\hline Metals & $\mathrm{Fe}(\%)$ & $\mathrm{Cu}(\%)$ & $\mathrm{Al}(\%)$ & $\mathrm{Si}(\%)$ & $\mathrm{C}(\%)$ & $\mathrm{S}(\%)$ & $\mathrm{P}(\%)$ \\
\hline Electrolytic $\mathrm{Fe}$ & & 0.004 & - & - & 0.005 & 0.005 & 0.004 \\
" $\mathrm{Cr}$ & 0.11 & - & 0.06 & 0.07 & 0.03 & 0.02 & 0.01 \\
\hline
\end{tabular}

* This paper was presented at the 1969 Spring Meeting of the Japan Institute of Metals. Reported originally in Japanese in J. Japan Inst. Metals, 34(1970), 850 : The 44th Report from The Foundation : The Research Institute of Electric and Magnetic Alloys, Sendai, Japan.

** The Foundation : The Research Institute of Electric and Magnetic Alloys, Sendai, Japan.

(1) H. Masumoto, S. Sawaya and M. Kikuchi : J.Japan Inst. Metals, 34 (1970), 850.

(2) On bcc type of the Fe-Cr alloys, R. M. Fisher, E. B. Dulis and K.R.Caroll : Trans. AIME, $197(1953)$, 69; R.D. Williams, H. W. Paxton : J. Iron Steel Inst., 185(1957), 358.

(3) M. Yamamoto : Sci. Rep. Tohoku Imp. Univ., 29 (1940), 113 ; J. Japan Inst. Metals, 4 (1940), 368.
(4) V. D. Yesin : Phys. Met. and Metallog., 20-2 (1965), 56.

(5) T. Fujiwara : Proc. Phys. Soc. Japan, 10 (1955), 355.

(6) H. Masumoto, H. Saitô and M. Kikuchi : J.Japan Inst. Metals, 30 (1966), 885 ; Sci. Rep. RITU, A-18 Suppl. (1966), 84.

( 7 ) H. Masumoto, H. Saitô, Y. Murakami and M. Kikuchi : J. Japan Inst. Metals, 32 (1968), 525 ; Trans. JIM, 10 (1969), 119.

(8) H. Masumoto, M. Kikuchi and S.Sawaya : J. Japan Inst. Metals, 33(1969), 1299 ; Trans. JIM, $11(1970), 176$.

(9) M. Yamamoto : J. Japan Inst. Metals, 5 (1941), 214 ; J. Appl. Phys. Japan, 10(1940), 199 ; H. Gengnagel und W.Schwab: Z. Metallk., 57 (1966), 281. 
polycrystal specimens about 3 and $0.5 \mathrm{~mm}$ in diameter were prepared from the molten alloy which was solidified at such a rate as to permit no crystal growth.

The specimens were all subjected to electropolishing, heating in a vacuum at $1000^{\circ} \mathrm{C}$ for about $1 \mathrm{hr}$, and cooling at a rate of $300^{\circ} \mathrm{C} / \mathrm{hr}$, and then finished off by electropolishing prior to measurement. The orientation distribution of all the single crystal specimens is indicated by the open circles in the stereographic projection $^{(10)}$ diagram of Fig. 1, and the orientations are summarized in Table 2.

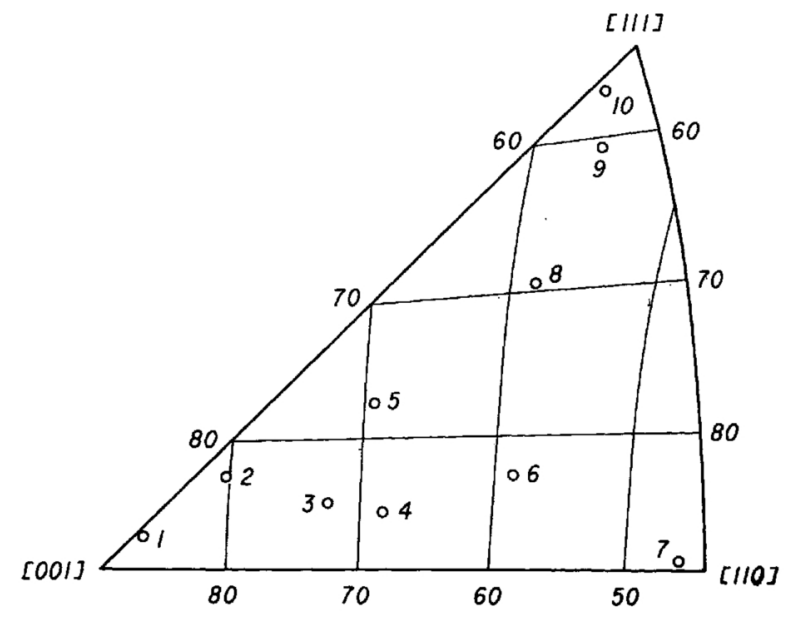

Fig. 1 Stereographic projection of the orientations in single crystals of $\mathrm{Fe}-19.43 \% \mathrm{Cr}$ alloy.

Table 2 Crystal orientations in single crystals of Fe- $19.43 \%$ Cr alloy

\begin{tabular}{r|c|c|c}
\hline No. & $\theta_{1}$ (degr.) & $\theta_{2}$ (degr.) & $\theta_{3}$ (degr.) \\
\hline 1 & 87.24 & 87.30 & 3.40 \\
2 & 80.01 & 82.45 & 12.24 \\
3 & 72.24 & 85.06 & 18.17 \\
4 & 68.39 & 85.45 & 21.40 \\
5 & 69.39 & 77.36 & 24.08 \\
6 & 58.36 & 82.15 & 32.34 \\
7 & 58.15 & 69.45 & 39.02 \\
8 & 46.39 & 89.09 & 43.22 \\
9 & 55.00 & 61.00 & 49.15 \\
10 & 56.00 & 57.00 & 51.20 \\
\hline
\end{tabular}

The thermal expansion was measured by the SuperInvar vertical-type dilatometer ${ }^{(11)}$ and the horizontal-type dilatometer, and the density was determined by weighing in water. Young's modulus was calculated from the resonance frequency of vibration of a specimen excited by means of a vibrator-controlled oscillator system $^{(12)}$ and the measured values of the thermal expansion coefficient and the density. The rigidity modulus measurement was carried out at room temperature by the torsional pendulum method ${ }^{(13)}$.

(10) C. S. Barrett : The struchure of Metals, The stereographic projection, McGraw-Hill, N. Y., (1952), 26 ; M. Yamamoto : Met. Phys., 6 (1960), 118.

(11) H. Masumoto and T. Kobayashi : J. Japan Inst. Metals, 12-6 (1948), 1 ; Sci. Rep. RITU, A-2 (1950), 856.

(12) Y. Shirakawa and I. Oguma : J. Japan Inst. Metals, 24(1960), 63 ; Sci. Rep. RITU, A-18 Suppl. (1966), 523.

(13) H. Masumoto : J. Japan Inst. Metals, 16 (1952), 126.

(14) W. Voigt : Lehrbuch der Kristallphysik, B. G. Teubner Leipzig, (1928), 410, 739, 741

\section{Results and Discussion}

\section{Thermal expansion}

Three specimens having rod axes nearest to the $<100\rangle,\langle 110\rangle$ and $\langle 111\rangle$ directions, respectively, were used to measure the thermal expansions in the temperature range of $-150^{\circ} \sim 250^{\circ} \mathrm{C}$, the results of which are shown in Fig. 2. As indicated by the figure, the thermal expansions are almost independent of the crystal directions and their expansion curves are nearly straight, with a thermal expansion coefficient of 10.23 $\times 10^{-6}$.

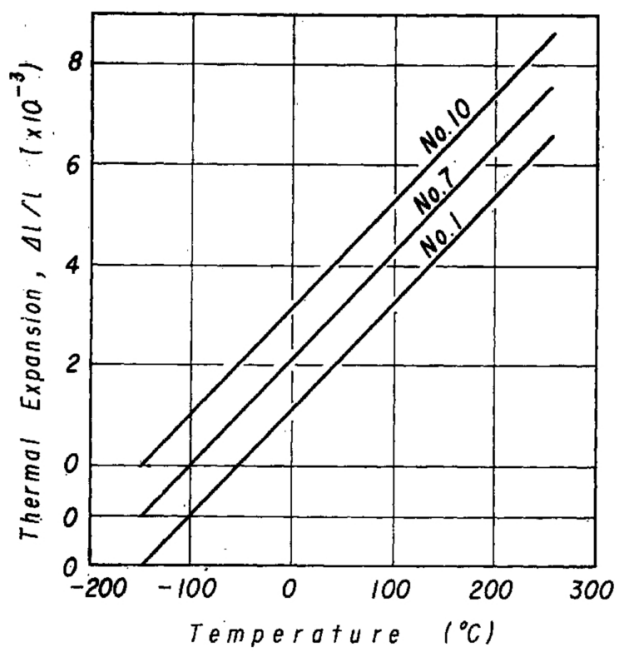

Fig. 2 Thermal expansion of single crystals in $\mathrm{Fe}-19.43 \% \mathrm{Cr}$ alloy.

\section{Young's modulus}

Young's modulus $E$ was calculated from the resonance frequency of vibration $(500 \sim 800 \mathrm{~Hz})$ and the measured values of the thermal expansion coefficient and the density $\left(7.72 \mathrm{~g} / \mathrm{cm}^{3}\right)$. The temperature dependence of $E$ is illustrated in Fig. 3. As shown in the figure, the value of $E$ is largest in specimen No. 10 near to the $<111\rangle$ direction and is smallest in specimen No. 1

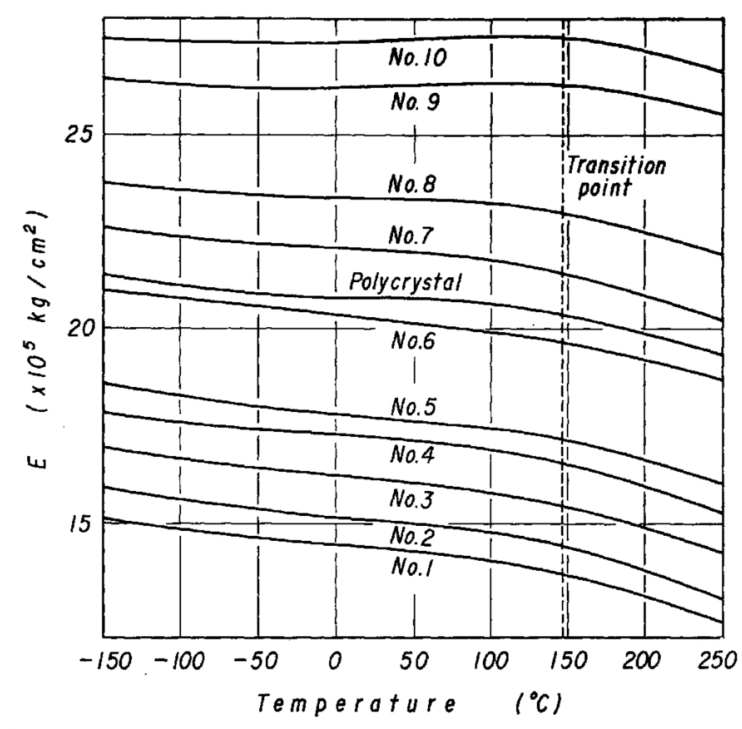

Fig. 3 Temperature dependence of Young's modulus in single crystals and a polycrystal of $\mathrm{Fe}-19.43 \% \mathrm{Cr}$ alloy. 
near to the $\langle 100\rangle$ direction, indicating a comparatively large anisotropy of $E$. In the specimen with the rod axis near to the $\langle 100\rangle$ direction, $E$ continuously decreases gradually with rise in temperature, but the rate of decrease in $E$ diminishes with the approach to the $\langle 111\rangle$ direction and $E$ shows a trend toward a slight increase at temperatures between $-50^{\circ} \sim 100^{\circ} \mathrm{C}$ in the specimen near to the $\langle 111\rangle$ direction.

However, since $E$ in an arbitrary direction cannot be obtained only from these measured values, the following relation $^{(14)}$ for the isometric crystals may be used :

$$
\frac{1}{E}=S_{11}-2\left(S_{11}-S_{12}-\frac{1}{2} S_{44}\right)\left(\alpha_{1}^{2} \alpha_{2}^{2}+\alpha_{2}^{2} \alpha_{3}^{2}+\alpha_{3}^{2} \alpha_{1}^{2}\right)
$$

where $S_{i j}$ is the elastic parameter and $\alpha_{i}$ and $\alpha_{j}$ are direction cosines of the rod axis with regard to the crystal axis. The orientation function $3 \Sigma \alpha_{i}^{2} \alpha_{j}^{2}$ is $0,1 / 4$ and $1 / 3$ in the $\langle 100\rangle,\langle 110\rangle$ and $\langle 111\rangle$ directions, respectively.

Figure 4 shows the relationship between $1 / E$ and $3 \Sigma \alpha_{i}^{2} \alpha_{j}^{2}$, in which the measured points lie on a nearly

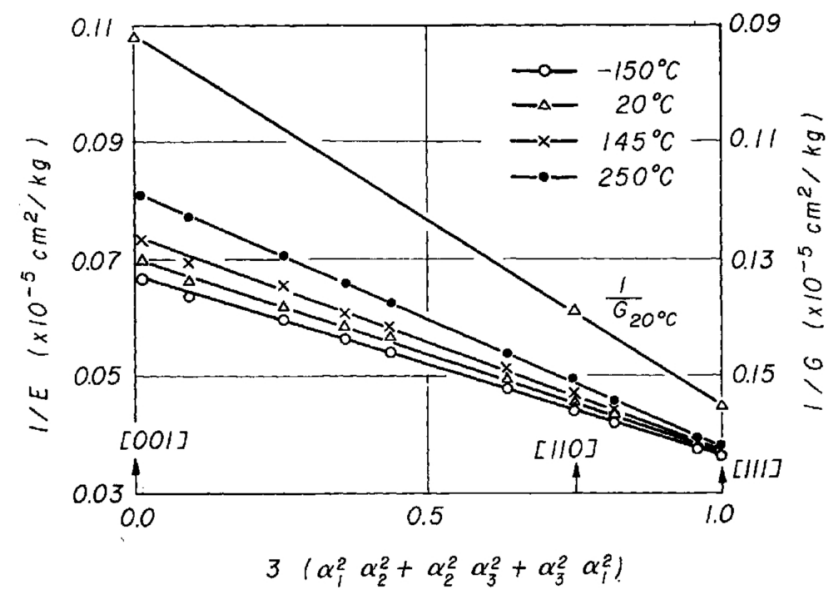

Fig. 4. Relations between reciprocals of Young's modulus $E$, rigidity modulus $G$ and orientation function $3\left(\alpha_{1}^{2} \alpha_{2}^{2}+\alpha_{2}^{2} \alpha_{3}^{2}+\alpha_{3}^{2} \alpha_{1}^{2}\right)$ in single crystals of $\mathrm{Fe}-19.43$ $\% \mathrm{Cr}$ alloy.

straight line as the evidence of validity of eq. (1). Accordingly, the values of $S_{11}$ and $S_{11}-S_{12}-(1 / 2) S_{44}$ at various temperatures can be calculated from the measured values of $E$ in eq. (1) using the least square method. The following relation may also be established in the (110) plane containing the three principal axes :

$$
\alpha_{1}^{2} \alpha_{2}^{2}+\alpha_{2}^{2} \alpha_{3}^{2}+\alpha_{3}^{2} \alpha_{1}^{2}=\frac{1}{4}\left(1+2 \cos ^{2} \theta-3 \cos ^{4} \theta\right)
$$

where $\theta$ is an angle between the [001] orientation and the rod axis of the specimen. By substituting eq. (2) into eq. (1), the values of $E$ in an arbitrary direction can be calculated. The temperature dependence of the calculated values of $S_{11}$ and $S_{11}-S_{12}-(1 / 2) S_{44}$, the temperature dependence of $E$ in the three principal directions and the orientation dependence of $E$ in the (110) plane at $-150^{\circ}, 145^{\circ}$ and $250^{\circ} \mathrm{C}$ are shown in Figs. 5, 6 and 7, respectively. As shown in Fig. 5, $S_{11}$ and $S_{11}-S_{12}-(1 / 2) S_{44}$ indicate a nearly similar variation with temperature; both of the calculated values increase linearly in the initial stage with increasing temperature and then increase parabolically from the

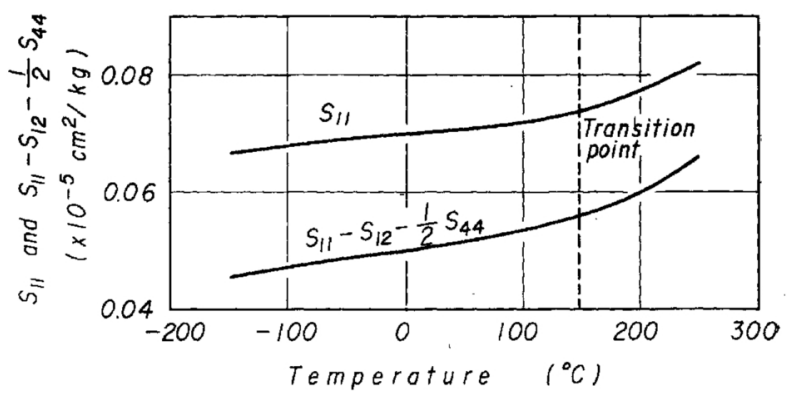

Fig. 5 Temperature dependence of calculated values of elastic parameters $S_{11}$ and $S_{11^{-}}-S_{12}-(1 / 2) S_{44}$ in single crystals of Fe-19. $43 \%$ Cr alloy.

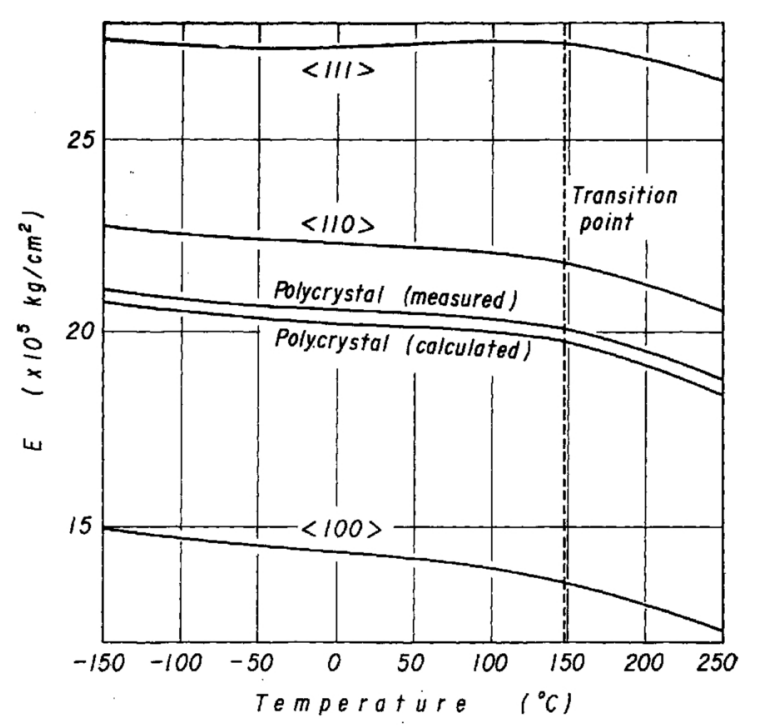

Fig. 6 Temperature dependence of calculated values of Young's modulus in three principal directions for single crystals of $\mathrm{Fe}-19.43 \% \mathrm{Cr}$ alloy.

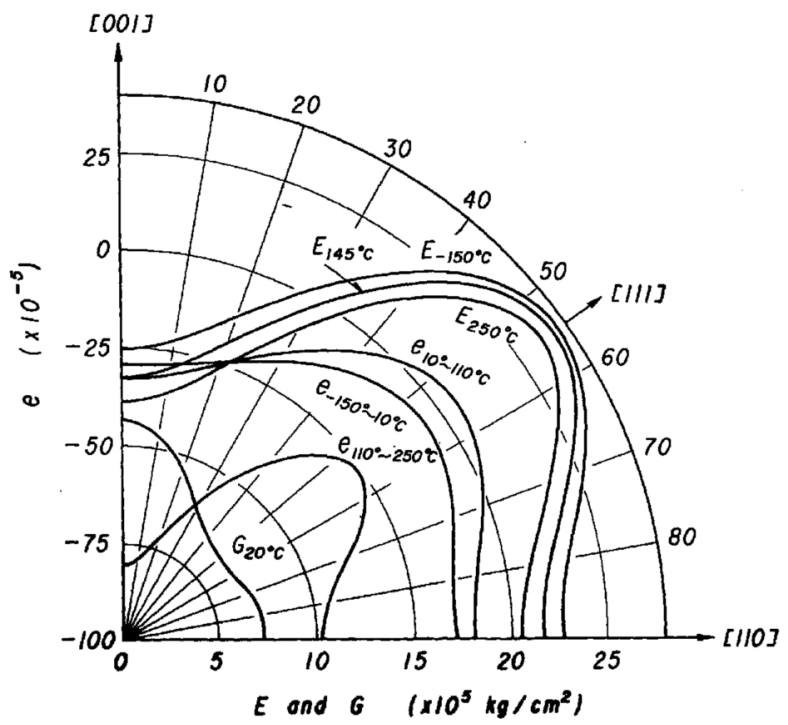

Fig. 7 Calculated values of Young's modulus $E$, rigidity modulus $G$ and temperature coefficient of Young's modulus $e$ in various orientations in the (110) plane of single crystals of $\mathrm{Fe}-19.43 \% \mathrm{Cr}$ alloy. 
vicinity of $150^{\circ} \mathrm{C}$. The value of $E$ at each temperature is highest in the $\langle 111\rangle$ direction and smallest in the $<100>$ direction as given in Fig. 6 .

The above results agree well with the following general relation for Young's moduli in the three principal directions in the isometric system as in the case of other metals and alloys ${ }^{(15)}$ :

$$
E_{<111>}>E_{<110>}>E_{<100>}
$$

When the temperature is raised, $E_{<100>}$ initially decreases linearly, but the decrement is accelerated gradually at temperatures above about $145^{\circ} \mathrm{C}$. The value of $E_{<110>}$ decreases rather steeply in the temperature range up to about $-100^{\circ} \mathrm{C}$, but the decrement becomes appreciably smaller with an increase in temperature and then decreases severely at temperatures higher than about $145^{\circ} \mathrm{C}$. $E_{<111>}$ decreases gradually with a rise in temperature and reaches a minimum value in the vicinity of $10^{\circ} \mathrm{C}$, after which the value continuously increases until a maximum value of about $110^{\circ} \mathrm{C}$ is attained. Thereafter, the value shows a gradual decreases again, augmenting the decrement at temperatures higher than about $145^{\circ} \mathrm{C}$. In the range of $10^{\circ} \sim$ $110^{\circ} \mathrm{C}$ the temperature coefficient of $E_{<111>}$ turns out positive. anisotropy $E_{<111>} \mid E_{<100>}$, in which the anisotropy increases gradually with a rise in temperature and indicates a slight bend between room temperature and 150 ${ }^{\circ} \mathrm{C}$, followed by a steep increase over $150^{\circ} \mathrm{C}$. The values of the elastic anisotropy at $-150^{\circ}, 20^{\circ}, 110^{\circ}$ and $250^{\circ} \mathrm{C}$ are as small as $1.85,1.92,1.98$ and 2.17, respectively, which are comparable with those of bodycentered cubic metals such as iron ${ }^{(16)}$. Table 3 shows the values of $E$ at room temperature in the three principal directions, the average temperature coefficient of $E$ at $-150^{\circ} \sim 10^{\circ} \mathrm{C}, 10^{\circ} \sim 110^{\circ} \mathrm{C}$ and $110^{\circ} \sim 250^{\circ} \mathrm{C}$ and the values of elastic anisotropy at room temperature.

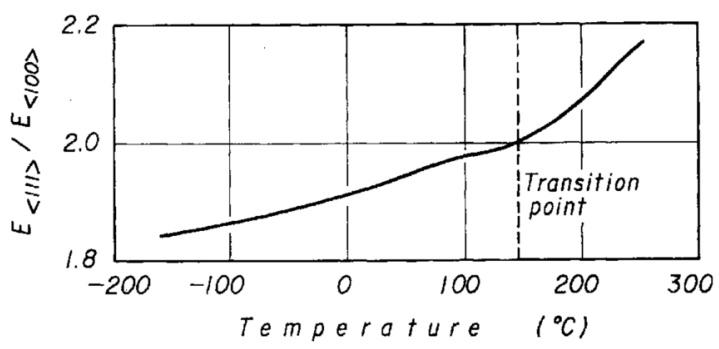

Fig. 8 Temperature dependence of calculated values of elastic anisotropy $E_{<111}>/ E_{<100}>$ in single crystals of $\mathrm{Fe}-19.43 \% \mathrm{Cr}$ alloy.

Table 3 Calculated values of Young's modulus $E$, rigidity modulus $G$, temperature coefficient of Young's modulus $e$ in

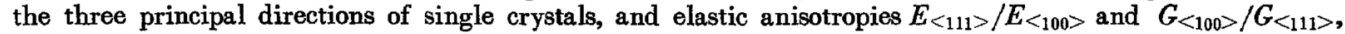
and volume compressibility $\kappa$ for $\mathrm{Fe}-19.43 \% \mathrm{Cr}$ alloy

\begin{tabular}{|c|c|c|c|c|c|c|c|c|}
\hline & $E$ & $G$ & \multirow{2}{*}{$E_{<111>} / E_{<100>}$} & \multirow{2}{*}{$G_{<100>} / G_{<111>}$} & \multirow{3}{*}{$\left(\times 10^{-5} \mathrm{~cm}^{\kappa} / \mathrm{kg}\right)$} & \multirow{2}{*}{\multicolumn{3}{|c|}{$\begin{array}{c}e \\
\left(\times 10^{-5}\right)\end{array}$}} \\
\hline & \multicolumn{2}{|c|}{$\left(\times 10^{5} \mathrm{~kg} / \mathrm{cm}^{2}\right)$} & & & & & & \\
\hline & \multicolumn{4}{|c|}{$20^{\circ} \mathrm{C}$} & & $-150^{\circ} \sim 10^{\circ} \mathrm{C}$ & $10^{\circ} \sim 110^{\circ} \mathrm{C}$ & $110^{\circ} \sim 250^{\circ} \mathrm{C}$ \\
\hline $\begin{array}{c}\langle 100\rangle \\
\langle 110\rangle \\
\text { Polycrystal } \\
\langle 111\rangle\end{array}$ & $\begin{array}{c}14.22 \\
22.23 \\
27.37 \\
20.20 \\
-\end{array}$ & $\begin{array}{r}11.36 \\
7.21 \\
6.43 \\
7.88 \\
-\end{array}$ & $\begin{array}{l}\bar{z} \\
\overline{1.92}\end{array}$ & $\begin{array}{l}\bar{z} \\
\overline{1.77}\end{array}$ & $\begin{array}{c}- \\
\overline{-} \\
0.0648 \\
-\end{array}$ & $\begin{array}{r}-29.20 \\
-14.26 \\
-4.74 \\
-11.72 \\
-\end{array}$ & $\begin{array}{r}-32.77 \\
-9.85 \\
+4.71 \\
-9.90 \\
-\end{array}$ & $\begin{array}{l}-80.78 \\
-49.26 \\
-25.84 \\
-56.49 \\
-\end{array}$ \\
\hline
\end{tabular}

As shown in Fig. 7, the value of $E$ is very low at any given temperature in the [001] orientation, but with increasing angle from the orientation, it becomes larger gradually and reaches the highest value in the [111] orientation. Then the value shows a gradual decrease with further increase in angle up to the [110] orientation. The orientation dependence of the mean temperature coefficient of $E$ at $-150^{\circ} \sim 10^{\circ} \mathrm{C}, 10^{\circ} \sim 110^{\circ} \mathrm{C}$ and $110^{\circ} \sim 250^{\circ} \mathrm{C}$ is also shown in the figure. It is to be noted that $e_{10^{\circ} \sim 110^{\circ} \mathrm{C}}$ is negative from the [001] orientation to about $44^{\circ}$, beyond which the value turns out positive and the positive value is sustained up to the angle of $64^{\circ}$ after reaching the positive maximum value in the [111] orientation. Thereafter, the value becomes negative again and the negative value is continuously augmented up to the [110] orientation. Both $e_{-150^{\circ} \sim 10^{\circ} \mathrm{C}}$ and $e_{110^{\circ} \sim 250^{\circ} \mathrm{C}}$ are negative in the entire range of orientations investigated.

Figure 8 shows the temperature dependence of elastic

(15) $\mathrm{Cu}(f c c)$, W. C. Overton and J.Gaffney : Phys. Rev., 98 $(1955), 969 ; \mathrm{Fe}(b c c)$, J. A. Rayne and B. S. Chandrasekhar : Phys. Rev., 122 (1961), 1714; Fe-Ni alloy ( $f c c)$, G. A. Alers, J.R. Neighbours and H. Sato : J.Phys. Chem. Solids, 13 (1960), 40; Fe-Al alloy (bcc), K. Numakura : J. Phys. Soc. Japan, 16 (1961), 2344.
The value of $E$ in the quasi-isotropic polycrystallite has heretofore been calculated by Voigt ${ }^{(14)}, \operatorname{Reu}^{(17)}$ and other workers ${ }^{(18) \sim(22)}$. Here, the value of $E$ for the polycrystal specimen can be derived from Reuß' equation

$$
E_{p}=\frac{5}{3 S_{11}+2 S_{12}+S_{44}}
$$

by using the mean value of the strain component $S_{i j}$ on the assumption that the straining condition is equal for all the crystallites. A comparison between the data calculated from the above relation and the measured values of $E_{p}$ for the quasi-polycrystal specimen slowcooled after melting is shown in Fig. 6 , both being in good agreement. The rigidity modulus of the polycrystal

(16) D. H. Chung and W. R. Buessen : J. Appl. Phys., 38 (1967), 2010.

(17) A. Reu $\beta$ : Z. angew. Math u Mechn., 9(1929), 49.

(18) W. A. Wooster : Crystal Physics, 1938, Cambridge.

(19) W. Köster : Z. Metallk., 35 (1943), 57.

(20) R. F. S. Hearmon : Rev. Mod. Phys., 18 (1946), 409.

(21) E. Kröner : Z. Phys., 151 (1958), 504.

(22) G. Kneer : phys. stat. sol., 9 (1965), 825.

(23) confer p. 410 in (14) 
specimen measured at room temperature is also listed in Table 3.

\section{Volume compressibility}

The following relation holds for the volume compressibility $\kappa, E$ and $G$ :

$$
\kappa=\frac{3(3 G-E)}{E G}
$$

Using the measured values of $E$ and $G, \kappa$ can be derived from the above relation as given in Table 3 .

\section{Elastic parameter and elastic constant}

Since there is a relation

$$
\kappa=3\left(S_{11}+2 S_{12}\right)
$$

between $\kappa$ and $S_{i j}$, the value of $S_{12}$ can be obtained using the measured values of $S_{i j}$ in Fig. 5 and $\kappa$ in Table 3 . At the same time, the value of $S_{44}$ at $20^{\circ} \mathrm{C}$ can be calculated from the value of $S_{11}-S_{12}-(1 / 2) S_{44}$ in Fig. 5 as shown in Table 4. The principal elastic constant $C_{i j}$ can be derived from the following relations :

Table 4 Calculated values of elastic parameter $S_{i j}$ and elastic constant $C_{i j}$ at $20^{\circ} \mathrm{C}$ of the $\mathrm{Fe}-19.43 \% \mathrm{Cr}$ alloy

\begin{tabular}{c|c|c|c}
\hline$S_{i j}$ & $\left(\times 10^{-5} \mathrm{~cm}^{2} / \mathrm{kg}\right)$ & $C_{i j}$ & $\left(\times 10^{5} \mathrm{~kg} / \mathrm{cm}^{2}\right)$ \\
\hline$S_{11}$ & 0.0703 & $C_{11}$ & 22.41 \\
$S_{12}$ & -0.0243 & $C_{12}$ & 11.84 \\
$S_{44}$ & 0.0880 & $C_{44}$ & 11.36 \\
\hline
\end{tabular}

$$
\begin{aligned}
& C_{11}=\frac{S_{11}+S_{12}}{\left(S_{11}-S_{12}\right)\left(S_{11}+2 S_{12}\right)}, \\
& C_{12}=\frac{-S_{12}}{\left(S_{11}-S_{12}\right)\left(S_{11}+2 S_{12}\right)}, \\
& C_{44}=\frac{1}{S_{44}},
\end{aligned}
$$

The values of $C_{i j}$ at $20^{\circ} \mathrm{C}$, calculated from the above relations, are tabulated in Table 3 , but Cauchy's relation, $C_{12}=C_{44}{ }^{(23)}$, does not hold for the cubic crystal system $^{(24)}$.

\section{Rigidity modulus of single crystals}

Since the rigidity modulus $G$ and $S_{i j}$ for the principal directions in the isometric system crystal specimen have the following relation :

$$
\frac{1}{G}=S_{44}+4\left(S_{11}-S_{12}-\frac{1}{2} S_{44}\right)\left(\alpha_{1}^{2} \alpha_{2}^{2}+\alpha_{2}^{2} \alpha_{3}^{2}+\alpha_{3}^{2} \alpha_{1}^{2}\right),
$$

the values of $G$ for various orientations and temperatures can be calculated by substituting the predetermined values of $S_{i j}$ into the above relation. The results thus obtained are shown in Fig. 7 and Table 3, from which

(24) E. Gones: Ann. Phys., 17 (1933), 233 ; E. Gones and J. Weerts : Phys. Zeit., 37 (1936), 321.

(25) M. Yamamoto : J. Japan Inst. Metals, 6 (1942), 331. it is clear that $G$ is largest in the $\langle 100\rangle$ direction and smallest in the $\langle 111\rangle$ direction. This tendency is similar to that of pure metals such as iron and nickel in the cubic crystal system ${ }^{(25)}$ and Diaflex ${ }^{(26)}$. The relationship between $1 / G$ and the direction function at $20^{\circ} \mathrm{C}$ is shown in Fig. 4, and the curves are almost linear. The anisotropy of $G, G_{<100>} / G_{<111>}$, is illustrated in Table 3 , indicating small values as in the case of $E$.

As mentioned already, it has been made clear that the temperature coefficient of Young's modulus in single crystals of the $\mathrm{Fe}-\mathrm{Cr}$ alloy containing $19.43 \% \mathrm{Cr}$ exhibits the highest positive value of $+4.71 \times 10^{-5}$ in the $\langle 111\rangle$ direction. It is very interesting to note that the $\mathrm{Fe}-19.43 \% \mathrm{Cr}$ alloy exhibits a positive temperature coefficient of Young's modulus at room temperature despite its fairly high magnetic transformation point. The authors will carry out further research to clarify the cause for this phenomenon.

\section{Conclusions}

Single crystals of the Fe-19.43\% Cr alloy prepared by the Tammann-Bridgman method, and subjected to slow cooling from $1000^{\circ} \mathrm{C}$ were measured so as to determine the thermal expansion and Young's modulus at $-150^{\circ} \sim 250^{\circ} \mathrm{C}$. Ther igidity modulus of the polycrystal specimen was also measured at room temperature. The results obtained are as follows :

(1) The thermal expansion of the single crystals determined at $-150^{\circ} \sim 250^{\circ} \mathrm{C}$ is isotropic and the expansion curves are almost linear, the linear coefficient of thermal expansion being $10.23 \times 10^{-6}$.

(2) The ealculated values of Young's modulus of the single crystals in the three principal directions and of the polycrystal specimen at $20^{\circ} \mathrm{C}$ are $E_{<100>}=14.22$ $\times 10^{5}, E_{<110>}=22.33 \times 10^{5}, \quad E_{<111>}=27.37 \times 10^{5}$ and $E_{\text {poly }}=20.20 \times 10^{5} \mathrm{~kg} / \mathrm{cm}^{2}$, among which the value of $E_{\text {poly }}$ is almost consistent with the measured one for the quasi-isotropic polycrystal specimen. The value of $E_{<111>}$ $\mid E_{<100\rangle}$ at $20^{\circ} \mathrm{C}$ is 1.92 , approaching the mean value of $b c c$ type materials with rise of temperature.

(3) Young's moduli in the $\langle 100\rangle$ and $\langle 110\rangle$ directions decreases linearly with the temperature, but the value in the $\langle 111\rangle$ direction shows a minimum in the vicinity of $10^{\circ} \mathrm{C}$ and a maximum at about $110^{\circ} \mathrm{C}$. The mean temperature coefficients of Young's modulus. in the three principal directions and the polycrystal specimen at $10^{\circ} \sim 110^{\circ} \mathrm{C}$ are $e_{<100>}=-32.77 \times 10^{-5}$, $e_{<110>}=-9.85 \times 10^{-5}, e_{<111>}=+4.71 \times 10^{-5}$ and $e_{\mathrm{poly}}$ $=-9.90 \times 10^{-5}$, respectively.

(4) The principal elastic parameters at $20^{\circ} \mathrm{C}$ are: $S_{11}=0.0703 \times 10^{-5}, S_{12}=-0.0243 \times 10^{-5}$ and $S_{44}=$ $0.0880 \times 10^{-5} \mathrm{~cm}^{2} / \mathrm{kg}$.

(5) The principal elastic constants at $20^{\circ} \mathrm{C}$ are $C_{11}=$ $22.41 \times 10^{5}, C_{12}=11.84 \times 10^{5}$ and $C_{44}=11.36 \times 10^{5} \mathrm{~kg}$. $/ \mathrm{cm}^{2}$, where Cauchy's relation $C_{12}=C_{44}$ does not hold.

(26) H. Masumoto, H. Saitô and M. Kikuchi : J.Japan Inst. Metals, 31 (1967), 263 ; Trans. JIM, 9 (1968), 257. 
(6) The rigidity modulus at $20^{\circ} \mathrm{C}$ in the three principal directions is calculated to be $G_{<100>}=11.36 \times 10^{5}$, $G_{<110>}=7.21 \times 10^{5}$ and $G_{<111>}=6.43 \times 10^{5} \mathrm{~kg} / \mathrm{cm}^{2}$, the anisotropy $G_{<100>} / G_{<111>}$ being 1.77 at $20^{\circ} \mathrm{C}$.

(7) The volume compressibility at $20^{\circ} \mathrm{C}$ is $0.0648 \times$ $10^{-5} \mathrm{~cm}^{2} / \mathrm{kg}$.

\section{Acknowledgments}

The authors wish to express their appreciation to Mr. S. Sawaya of their research institute for his cooperation in various measurements and also to the staff of the Research Section of Tohoku Tokushuko K. K. for chemical analysis of the alloys used. 